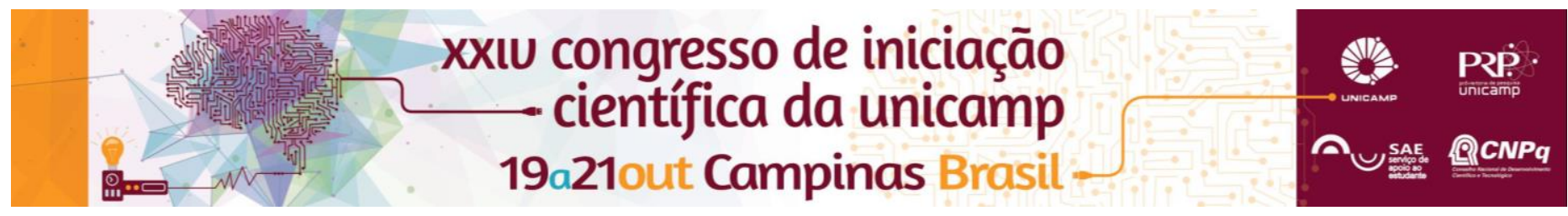

\title{
"Estrutura dos frutos formados por flores não polinizadas da espécie aclorofilada Pogoniopsis schenckii Cogn. (Orchidaceae: Vanilloideae)"
}

\author{
Ramom Nunes Ferreira (IC), Juliana Lischka Sampaio Mayer (PQ).
}

\section{Resumo}

A semente madura de orquídea possui um embrião sem instalação e diferenciação dos meristemas apicais, caulinar e radicular, e nem a formação de cotilédone. A associação com fungos é obrigatória para a germinação de algumas espécies, que são incapazes de absorver nutrientes de outra forma. O presente estudo analisou a estrutura anatômica e substâncias de reserva presentes nos frutos e embriões de Pogoniopsis schenckii e as diferenças no grau de diferenciação dos embriões nas sementes maduras.

Palavras-chave: Orquídea, Anatomia, Fruto.

\section{Introdução}

Orchidaceae possui mais de 24,500 espécies conhecidas (Dressler, 2005), sendo a subfamília Vanilloide composta por 3 subtribos, 15 gêneros e cerca de 175 espécies (Cameron et al., 1999). O gênero Pogoniopsis apresenta duas espécies que se desenvolvem sobre a matéria orgânica em florestas sombrias brasileiras, são saprófitas, aclorofiladas e amarelas (Pridgeon et al. 2003).

Frutos de Orchidaceae são conhecidos por serem cápsulas que possuem até 4 milhões de sementes (Arditti \& Ghani, 2000), possuindo 3 valvas férteis e 3 valvas estéreis. (Rasmussen \& Johansen, 2006). Devido ao pequeno tamanho da semente e ausência de endosperma muitas espécies necessitam de associações micorrízicas para germinar na natureza, assim na semente madura pode-se encontrar o embrião na fase globular na maioria das orquídeas (Arditti \& Ghani, 2000).

O presente estudo teve por objetivo analisar as substâncias de reserva e a anatomia de frutos e embriões zigóticos de Pogoniopsis schenckii. Como formação de linha de deiscência, desenvolvimento do funículo, formação do suspensor e diferenças no grau de diferenciação.

\section{Resultados e Discussão}

Foram coletadas flores e frutos de diferentes tamanhos para realizar a cronologia do desenvolvimento. Não houve formação da linha de deiscência e, na natureza, o fruto senesceu sem exposição das sementes. A semente possui tegumento liso espesso e marrom escuro e não há abertura evidente na região da micrópila. O embrião em desenvolvimento pode ser visto a partir de frutos de $1,2 \times 0,8 \mathrm{~cm}$, nesse tamanho também há 0 aumento do funículo.

Testes histoquímicos evidenciaram a constante presença de amido no fruto, havendo redução concomitante ao aparecimento de hifas e escurecimento do fruto. Foi detectada proteína em frutos de $2,5 \times 1,2 \mathrm{~cm}$ e em embriões de todos os tamanhos, além disso, embriões em frutos até $1,4 \times 0,9 \mathrm{~cm}$ apresentaram amido e para $2,5 \times 1,2 \mathrm{~cm}$ detectou-se lipídeos.
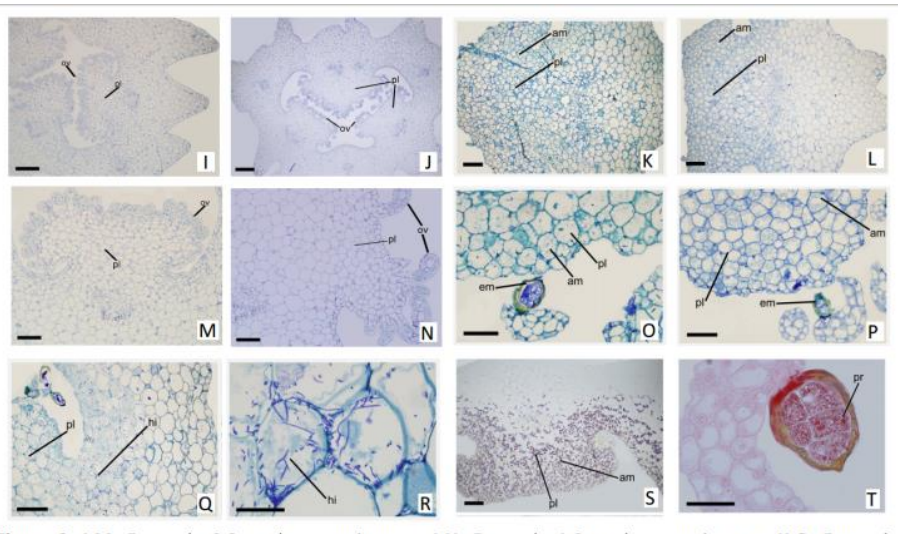

Figura 2. I;M. Fruto de $0,3 \mathrm{~cm}$ de comprimento. J;N. Fruto de $1,0 \mathrm{~cm}$ de comprimento. K;O. Fruto de $1,7 \times 1,2 \mathrm{~cm}$ de tamanho. L;P. Fruto de $2,2 \times 1,2 \mathrm{~cm}$ de tamanho. $\mathbf{I}-\mathbf{J}$. Fruto possui tamanho menor e não possui grãos de amido de reserva. K-L. Ocorre aumento no volume das células e surge reserva de amido na placenta e na parede do fruto. M. Óvulo em início de desenvolvimento. N. Óvulo em estágio mais desenvolvido. O-P. Frutos com sementes. Q-R. Fruto em estado inicial de senescências com hifas crencendo em meio aos grãos de amido em menor quantidade. S-T. Testes histoquímicos. S. Presença de amido evidenciada por Lugol. T. Presença de proteína no embrião evidenciada por Xylidine. am= amido em $=$ embrião hi= hifas ov= ovário $\mathrm{pl}=$ pplacenta pr= grânulos de proteína. Barras: J;K;L;Q;S= 200 $\mu \mathrm{m}, \mathrm{I} ; \mathrm{O} ; \mathrm{P}=$ $100 \mu \mathrm{m}, \mathrm{M} ; \mathrm{N} ; \mathrm{R}=50 \mu \mathrm{m}, \mathrm{T}=20 \mu \mathrm{m}$.

\section{Conclusões}

Pogoniopsis schenckii possui estruturas diferentes daquelas tipicamente encontradas em orquídeas, como fruto rico em reserva e indeiscente, e o melhor entendimento de suas estruturas pode colaborar para o entendimento da evolução do grupo.

\section{Agradecimentos}

A Unicamp e ao cnpq pelo apoio e suporte. A minha orientadora Juliana Mayer, pelo suporte e paciência.

Ao doutorando Carlos Pereira pelo auxílio no campo, aos meus companheiros de laboratório e departamento e todos que direta ou indiretamente contribuíram para a realização desse projeto.

${ }^{1}$ Dressler, L.R. How many orchid species? Selbyana, 26: 155-158, 2005.

2 Cameron, K.M.; Chase, M.W. Phylogenetic relationships of Pogoniinae (Vanilloideae, Orchidaceae). Journal of plant research, 112: 317-329, 1999.

3 Pridgeon, A.M.; et al. Genera Orchidacearum: Volume 3: Orchidoideae (Part 2), Vanilloideae. Oxford: Oxford University Press Inc., 2003.

4 Arditti, J.; Ghani. A.K.A. 2000. Tansley review No. 110 - Numerical and physical properties of orchid seeds and their biological implications. New Phytologist, 145: 367-421.

${ }^{5}$ Rasmussen, F. N.; Johansen, b. Carpology of Orchids.Selbyana, 27 44-53, 2006 